SCIENTIFIC REPORT

\title{
Inhibition of experimental diabetic cataract by topical administration of RS-verapamil hydrochloride
}

\author{
A Ettl, A Daxer, W Göttinger, E Schmid
}

Br J Ophthalmol 2004;88:44-47

Aim: To investigate the efficacy of verapamil eye drops for inhibition of diabetic cataract in rats.

Methods: Diabetes was induced in 69 male Sprague-Dawley rats by an intraperitoneal injection of streptozotocin $(65 \mathrm{mg} /$ $\mathrm{kg}$ body weight). One group (DV) of animals was treated by instillation of one drop of $0.2 \%$ RS-verapamil hydrochloride in both eyes three times daily for 8 weeks. The placebo treated group (D) received the vehicle solution only. After 8 weeks the lenses were removed, inspected, and photographed using bright and dark field illumination. The transmission of $\mathrm{He}-\mathrm{Ne}$ laser light was measured in the optical axis of each lens in order to determine the turbidity coefficient ( $t$ ) as a measure of central lens opacity. Following digital image analysis, the integrated density as a measure of central and mid-peripheral opacities was determined.

Results: Lenses of both groups developed peripheral cortical opacities not affecting the optical axis. Advanced and paracentral cortical opacities were present in $10(16.7 \%)$ of the placebo treated lenses (D) and two $(3.8 \%)$ of the verapamil treated lenses (DV). Complete corticonuclear cataract developed in four $(6.7 \%)$ of the lenses from group $D$ but none of the lenses from group DV. The mean lens turbidity $t$ was determined to be 0.019 (SEM 0.002) $\mathrm{mm}^{-1}$ $(\mathrm{n}=52)$ in the verapamil treated diabetic rats (DV) and $0.042(0.008) \mathrm{mm}^{-1}(\mathrm{n}=60)$ in the placebo treated group (D). This difference was statistically significant ( $p=0.0054$ ). The mean integrated density was 274.91 (22.5) in group D $(n=60)$ and 196.28 (20.7) in group DV $(n=37)$. This difference was also significant ( $p=0.0037$ ).

Conclusion: Verapamil eye drops $0.2 \%$ administered three times daily are effective in inhibiting the progression of lens opacities in streptozotocin diabetic rats.

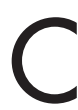
ataract is one of the major causes of blindness worldwide and diabetes is the most important risk factor for cataract in western countries. ${ }^{1}$ Possible pathophysiological mechanisms include activation of the polyol pathway causing increased hydration, ${ }^{2}$ non-enzymatic glycosylation with cross linking of proteins, ${ }^{3}$ and calpain mediated proteolysis. ${ }^{4}$ Duncan and coworkers ${ }^{5}$ have pointed out the key role of calcium in the pathogenesis of cataract. ${ }^{6}$ Increased levels of $\mathrm{Ca}^{2+}$ in the lens induce opacification in vitro $^{78}$ and have been measured in human lenses with age related cataract. ${ }^{5}$ Non-specific cation channels in lens membranes ${ }^{10}$ have been suggested to cause the age related increase in calcium. ${ }^{11}$

The greatest increase in free $\mathrm{Ca}^{2+}$ levels has been measured in opaque lens regions. ${ }^{12}$ The increased $\mathrm{Ca}^{2+}$ concentration leads to formation of high molecular weight proteins with increased light scattering ${ }^{13}$ and reduction of gap junction permeability with disintegration of lens fibres. ${ }^{14}$
Many anti-cataractogenic agents, such as aldose reductase inhibitors, have been described so far, but owing to lack of success in patients, no drug has yet been approved for clinical use. $^{15} 16$

Previously, it had been shown that diabetic ${ }^{17} 18$ or galactosaemic ${ }^{19}$ cataract in rats can be prevented by high dose oral or subcutaneous administration of verapamil without changing serum glucose levels. However, a systemic high dose administration would not be applicable in patients because of unacceptable side effects.

Recently, we have demonstrated, that RS-verapamil hydrochloride in aqueous solution readily penetrates into the eye after topical administration in rabbits without producing plasma drug levels that could lead to systemic side effects. ${ }^{20}$

The purpose of this study was to investigate whether a topical formulation of verapamil may inhibit the progression of diabetic lens opacities.

\section{METHODS}

\section{Animals}

Eighty male Sprague-Dawley rats initially weighing 150$200 \mathrm{~g}$ were randomly assigned to the following groups: C (normal controls), V (healthy rats treated with verapamil eye drops only), D (diabetic rats treated with placebo eye drops-that is, vehicle solution), DV (diabetic rats treated with verapamil eye drops). Slit lamp examinations were performed at 6 weeks. Eight weeks following diabetes induction by an intraperitoneal injection of streptozotocin (STZ) at a dose of $65 \mathrm{mg} / \mathrm{kg}$ body weight, the eyes were enucleated following cervical dislocation under ether anaesthesia and the lenses were dissected free and kept in a cell culture dish with isotonic Dulbecco's phosphate buffered saline (PBS). Seven non-responders to STZ (blood glucose measured using an enzymatic test $<150 \mathrm{mg} / 100 \mathrm{ml}$ ) and six animals that died before the end of the experiment were excluded leaving 67 animals in the investigation. The protocol was in accordance with the ARVO resolution on the use of animals in research.

\section{Treatment}

Verapamil eye drops $0.2 \%$ (305 mosM, pH 7.1) were prepared by dilution of $8 \mathrm{ml}$ of the intravenous solution containing $2.5 \mathrm{mg} / \mathrm{ml}$ RS-verapamil hydrochloride and $8.5 \mathrm{mg} / \mathrm{ml} \mathrm{NaCl}$ (Isoptin, Knoll, Ludwigshafen, Germany) with $1 \mathrm{ml}$ phosphate buffer $\mathrm{pH} 6.85$ (containing $264 \mathrm{mg} 4 \%$ sodium dihydrogen phosphate, $725 \mathrm{mg}$ of $4 \%$ sodium monohydrogen phosphate, and $10 \mathrm{mg}$ water) and $1 \mathrm{ml} 2 \%$ methylhydroxypropylcellulose (Dispersa, Hettlingen, Germany).

Animals from groups DV and V were treated by instillation of $12 \mu \mathrm{l}$ of $0.2 \%$ verapamil eye drops three times daily for 2 months. Rats from group D were treated by instillation of the vehicle solution only. 


\section{Evaluation of opacities}

The lenses were inspected for opacities under an operating microscope and photographed using bright field and dark field illumination.

The lenses were centred under the $1 \mathrm{~mm}$ wide beam of a He-Ne laser (Laser Components, Groebenzell, Germany) with a power of $0.1 \mathrm{~mW}$. Then, the voltage in a collecting photodiode mounted under the cell culture dish, was measured. The turbidity $\mathrm{t}$ as a measure of opacity was calculated for each lens using Lambert-Beer's equation ${ }^{21}$ :

$$
\mathrm{t}\left(\mathrm{mm}^{-1}\right)=\left(\ln \mathrm{I}_{\mathrm{o}} / \mathrm{I}\right) \cdot \mathrm{d}^{-1}
$$

where I is the intensity of the laser light transmitted through the lens, Io is the intensity of the laser beam transmitted through the cell culture dish without lens, and $d$ is the central thickness of each lens measured using a micrometer eye piece.

Digital image analysis was performed using the software Adobe PhotoShop 5.0 and the public domain software NIH Image 1.62..22 23 The digitised images consisted of pixels of different grey values between zero (white) and 255 (black). Since dark field illumination was used, clear lens areas resulted in white portions on the negatives whereas lens turbidities were seen as dark parts. After spatial calibration and correcting all images for uneven background illumination, the opacities in the central area comprising $70 \%$ of the lens diameter were evaluated, thus excluding the circular reflexes of the illumination device near the lens equator. The integrated density (ID) ${ }^{22} 23$ of each lens was calculated as follows:

\section{$\mathrm{ID}=\mathrm{N}^{*}$ (mean grey value - background $)$}

where $\mathrm{N}$ is the pixel number within the central $70 \%$ of the lens area, "background" is the most common pixel value after smoothing the histogram..$^{22}$ The ID was expected to be low in clear lenses and high in opacified lenses.

\section{RESULTS}

Microscopic inspection of the lenses revealed that peripheral cortical opacities were present in both placebo treated diabetic lenses (D) and verapamil treated diabetic lenses (DV). Diffuse cortical opacities involving the paracentral area were seen in $10(16.7 \%)$ lenses of group D and in only two $(3.8 \%)$ lenses of group DV. Complete corticonuclear cataract was observed in four $(6.7 \%)$ of the placebo treated diabetic lenses but none of the verapamil treated diabetic lenses (fig 1).

The turbidity (mean (SEM)) as a measure of opacity in the optical axis of each lens, was $0.003(0.001) \mathrm{mm}^{-1}$ in group C $(\mathrm{n}=12), 0.002(0.001) \mathrm{mm}^{-1}$ in group $\mathrm{V}(\mathrm{n}=10), 0.042$ $(0.008) \mathrm{mm}^{-1}$ in group D $(\mathrm{n}=60)$, and $0.019(0.002) \mathrm{mm}^{-1}$ in group DV $(\mathrm{n}=52)$ (fig 2$)$. Mann-Whitney's $U$ test revealed that the turbidity in verapamil treated diabetic lenses was significantly $(p=0.0054)$ lower than in placebo treated diabetic lenses.

The integrated density (mean (SEM)) was 96.89 (12.61) in group $C(n=12), 102.84(25.6)$ in group $V(n=10), 274.91$ $(22.5)$ in group D $(n=60)$, and $196.28(20.7)$ in group DV $(\mathrm{n}=37)$ (fig 3). The Kruskal-Wallis test showed a significant difference between the four groups $(\mathrm{p}<0.0001)$ and MannWhitney's U test calculated a significant difference between placebo treated and verapamil treated diabetic lenses $(\mathrm{p}=0.0037)$.

The blood glucose levels (mean (SEM)) at 2 months were $373(12) \mathrm{mg} / 100 \mathrm{ml}$ in group $\mathrm{D}(\mathrm{n}=30), 343(13) \mathrm{mg} / 100 \mathrm{ml}$ in group DV $(\mathrm{n}=23)$ (no significant difference between $\mathrm{D}$ and V), $51.6(2.2) \mathrm{mg} / 100 \mathrm{ml}$ in group $\mathrm{C}(\mathrm{n}=3)$ and 51.8
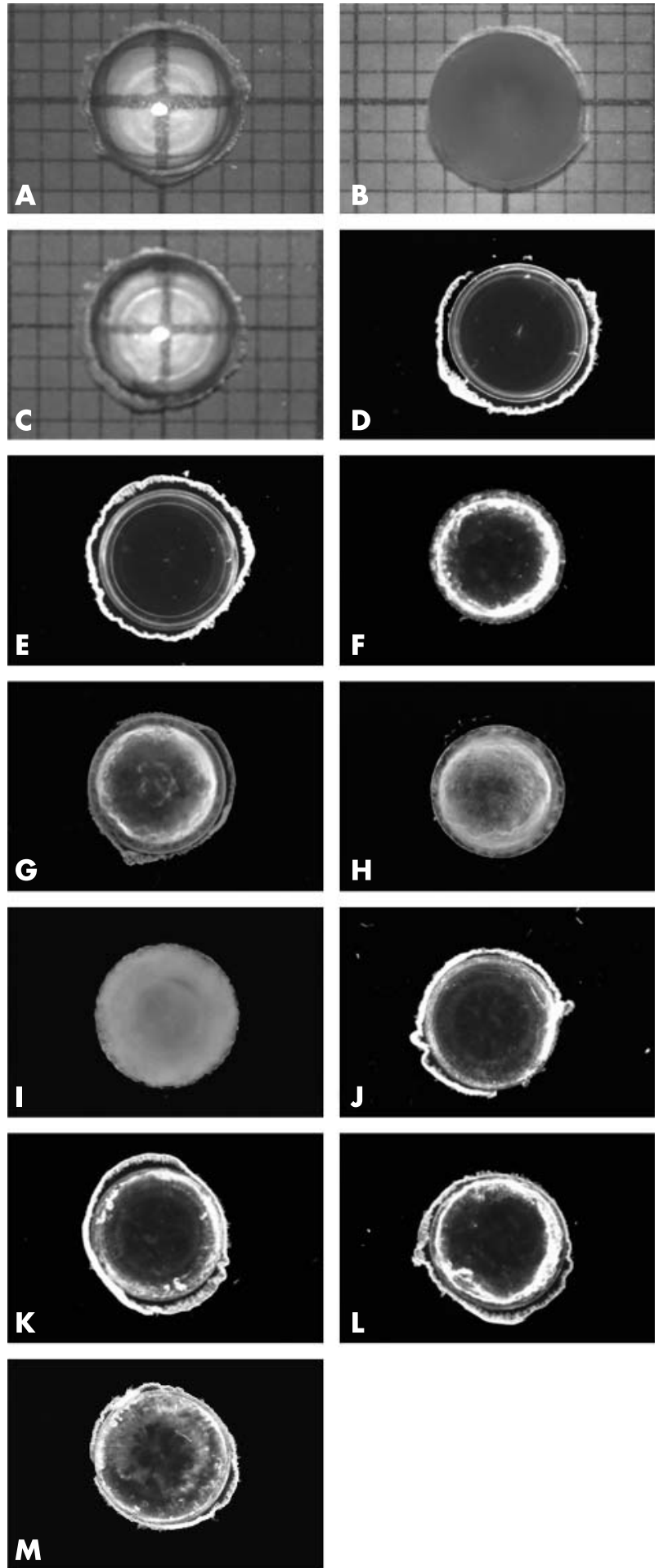

Figure 1 Bright field $(A-C)$ and dark field $(D-M)$ microphotographs of rat lenses. (A) Untreated normal lens (group C); (B) placebo treated diabetic lens (group D) showing total corticonuclear cataract; (C) verapamil treated diabetic lens (group DV); (D) untreated normal lens; (E) verapamil treated normal lens; $(F, G)$ placebo treated diabetic lenses showing mainly peripheral cortical opacities; $(\mathrm{H})$ placebo treated diabetic lens showing diffuse cortical opacities; (I) placebo treated diabetic lens showing total corticonuclear opacity; $(J)$ verapamil treated diabetic lens showing mild peripheral cortical opacities; (K, L) verapamil treated diabetic lenses showing dense peripheral cortical opacities; $(M)$ verapamil treated diabetic lens with diffuse cortical opacities representing one of the most opaque lenses of group DV. 


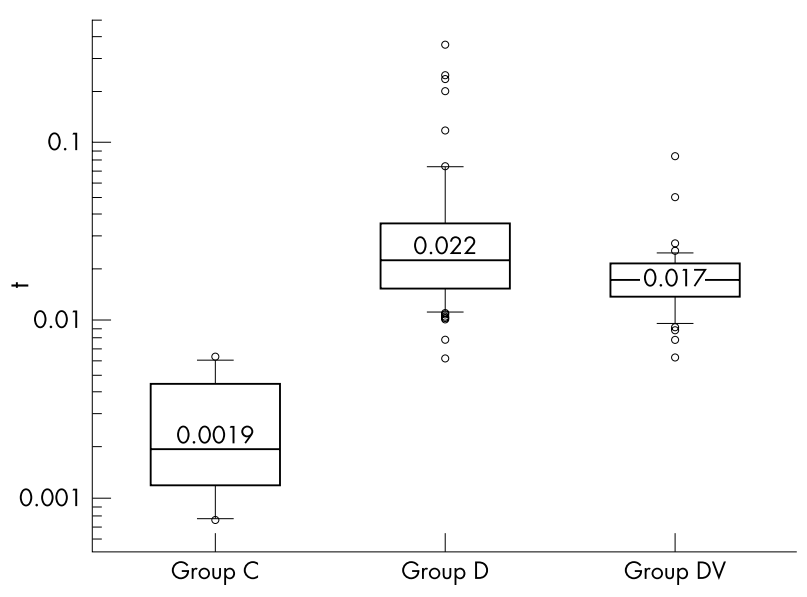

Figure 2 Box plots of the t values $\left(\mathrm{mm}^{-1}\right)$ from untreated, normal lenses (C), placebo treated diabetic lenses (D), and verapamil treated diabetic lenses (DV). The horizontal line inside the box represents the median (50th percentile), the borders of the box the 25th and the 75th percentile and the ends of the bars the 10th and the 90th percentile of the t values. Mann-Whitney's $U$ test yielded a significant difference between group $D$ and DV. Note the logarithmic scale of the $y$ axis.

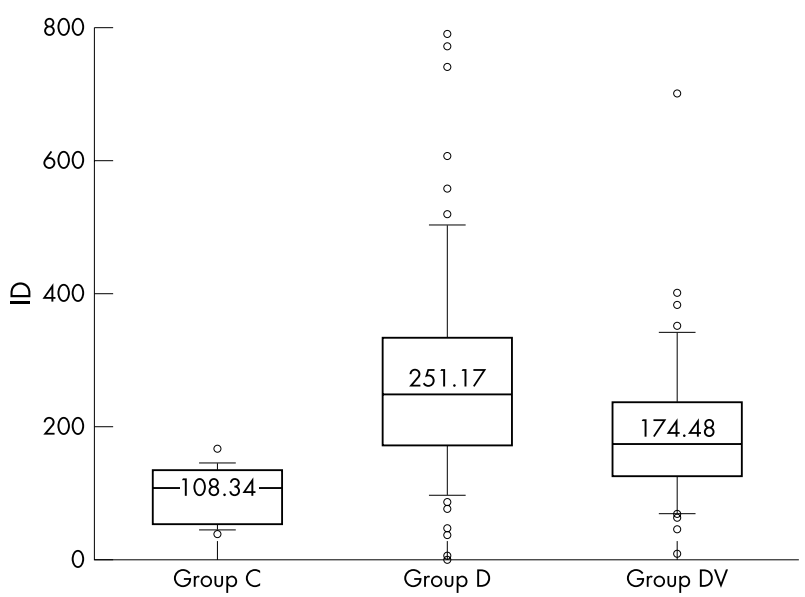

Figure 3 Box plots of the integrated density (ID) values from untreated, normal lenses (C), placebo treated diabetic lenses (D), and verapamil treated diabetic lenses (DV). The horizontal line inside the box represents the median, the borders of the box the 25th and 75 th percentile and the bars the 10th and the 90th percentile of the integrated density values. Mann-Whitney's $U$ test yielded a significant difference between group D and DV.

(1.6) $\mathrm{mg} / 100 \mathrm{ml}$ in group $\mathrm{V}(\mathrm{n}=4)$. On slit lamp examinations at 6 weeks, there were no signs of conjunctival or corneal side effects.

\section{DISCUSSION}

This investigation demonstrated that a topical administration of verapamil inhibited cataract formation in streptozotocin diabetic rats. A complete prevention of cortical opacification was not possible in this diabetes model where severe lens opacities developed within a short time. However, verapamil prevented the formation of opacities in the optical axis and the progression to total corticonuclear cataract. The mode of action of verapamil as an anti-cataractogenic drug is possibly related to an inhibition of lenticular calcium overload. ${ }^{17}{ }^{18}$ However, its effect may not entirely be ascribed to changes in lens calcium because it not only inhibited cortical opacities (with known high calcium levels) but also nuclear cataract (with known low calcium levels ). ${ }^{9}$ Although electrophysiological studies have revealed that lens cells contain $\mathrm{Ca}^{2+}$ channels with similar properties as in excitable tissues, ${ }^{24}$ the pharmacological profile of these ion channels has not yet been characterised. It has been suggested that the inhibition of $\mathrm{Ca}^{2+}$ induced damage of lens fibres by verapamil is mediated by L-type calcium channels. ${ }^{25-27}$ However, in experiments using the L-type calcium channel selective radioligands $(-)-\left({ }^{3} \mathrm{H}\right)$-desmethoxyverapamil and $(+)-\left({ }^{3} \mathrm{H}\right)$ isradipine, we had no evidence of saturable, high affinity binding sites in membrane preparations from bovine lens epithelial cells indicating that L-type calcium channels either occur at a much lower density than in electrically excitable cells or are absent (unpublished results).

Calcium channel blockers are known to interact with a variety of other calcium transport structures including non-Ltype calcium channels. ${ }^{28}$ Some of these structures, such as $\mathrm{Ca}^{2+}$ ATPase, ${ }^{29-31} \mathrm{Na}^{+} / \mathrm{Ca}^{2+}$ transporter ${ }^{32}{ }^{33}$ and receptor mediated calcium entry pathways ${ }^{34}$ have been identified in lens membranes. Acetylcholine induced lens membrane oscillations, for example, can be blocked by the L-type $\mathrm{Ca}^{2+}$ channel blocker nifedipine. ${ }^{35}$ D 600 , the methoxy analogue of verapamil, has been suggested to block calcium influx into lens cells. $^{36}$ Possibly, the anti-cataractogenic action of verapamil is related to blockage of non-L-type receptor operated calcium channels.

Verapamil also prevents the accumulation of sorbitol in rat lenses and has therefore been suggested to act as an aldose reductase inhibitor (ARI) ${ }^{37}$ (despite a low inhibition constant $^{38}$ ). Interestingly, ARIs may also have actions not related to the polyol pathway. ${ }^{39}$

Further investigations using a variety of other compounds including pure stereoisomers of calcium antagonists are needed to identify the pharmacological profile of the anticataractogenic effect of verapamil. Since many pathophysiological aspects of diabetic cataract ${ }^{12}{ }^{40}$ resemble the changes in senile cataract, further evaluation of verapamil for the prevention of senile cataract is warranted. In patients suffering from cataract and glaucoma, verapamil eye drops may be beneficial for both diseases since they have also been demonstrated to lower intraocular pressure. ${ }^{41}$

\section{CONCLUSION}

A topical administration of the calcium antagonist RSverapamil in a concentration of $2 \mathrm{mg} / \mathrm{ml}$ inhibits cataract formation and progression in a diabetic animal model.

\section{ACKNOWLEDGEMENTS}

The authors thank Professors H Glossman and J Striessnig (Institute for Biochemical Pharmacology, University of Innsbruck), $\mathrm{Dr} \mathrm{H}$ Dietrich, and Mag. E Semenitz for methodological support. Funding was provided by the Raiffeisen Bank/University of Innsbruck.

\section{Authors' affiliations}

A Ettl, A Daxer, W Göttinger, E Schmid, Department of Ophthalmology, University of Innsbruck, Austria

A Ettl, Department of Neuro-Ophthalmology, Oculoplastic and Orbital Surgery, Central Hospital, Pölten, Austria

A Daxer, Eye Center, Linz, Austria Correspondence to: Armin Ettl, MD, PhD, Neuro-Ophthalmology,
Zentraltrankenhaus Posffach 176, A-3100 St Pölten, Austria; a.ett@

kh-st-poelten.at

Accepted for publication 26 April 2003

Preliminary results of this study were presented at the annual meetings of the AER in Granada in 1993 and the ARVO in Fort Lauderdale in 1995. 


\section{REFERENCES}

1 Caird Fl, Hutchinson M, Pirie A. Cataract extraction and diabetes. Br J Ophthalmol 1965;49:466-71.

2 van Heyningen $\mathbf{R}$. Formation of polyols by the lens of the rat with sugar cataract. Nature 1959:184:194-5.

3 van Boekel MA, Hoenders HJ. Glycation of crystallins in lenses from aging and diabetic individuals. FEBS Lett 1992;314:1-4.

4 Azuma M, Shearer TR, Matsumoto T, et al. Calpain II in two in vivo models of sugar cataract. Exp Eye Res 1990;51:393-401.

5 Duncan G, Marcantonio JM, Tomlinson J. Lens calcium and cataract. In: Obrecht G, Stark LW, eds. Presbyopia research. New York: Plenum Press, 1991:33-40

6 Hightower KR. Cytotoxic effects of internal calcium on lens physiology: a review. Curr Eye Res 1985:4:453-9.

7 Hightower KR, Dering M. Development and reversal of calcium-induced opacities in vitro. Invest Ophthalmol Vis Sci 1984;25:1108-11.

8 Marcantonio JM, Duncan G, Rink H. Calcium-induced opacification and loss of protein in the organ-cultured bovine lens. Exp Eye Res 1986:42:617-30.

9 Duncan G, Jacob TJ. Calcium and the physiology of cataract. Ciba Found Symp 1984; 106:132-52.

10 Rae JL. The application of patch clamp methods to ocular epithelia. Curr Eye Res 1985;4:409-20.

11 Duncan G, Hightower KR, Gandolfi SA, et al. Human lens membrane cation permeability increases with age. Invest Ophthalmol Vis Sci 1989;30:1855-9.

12 Hightower KR, Riley MV, McCready J. Regional distribution of calcium in alloxan diabetic rabbit lens. Curr Eye Res 1989;8:517-21.

13 Giblin FJ, Hightower KR, Ragatzki PA, et al. Calcium-induced high molecular weight proteins in the intact rabbit lens. Exp Eye Res 1984;39:9-17.

14 Gandolfi SA, Duncan G, Tomlinson J, et al. Mammalian lens inter-fiber resistance is modulated by calcium and calmodulin. Curr Eye Res 1990;9:533-41.

15 Harding JJ. Pharmacological treatment strategies in age-related cataracts. Drugs Aging 1992;2:287-300.

16 Ao S, Kikuchi C, Ono T, et al. Effect of instillation of aldose reductase inhibitor FR74366 on diabetic cataract. Invest Ophthalmol Vis Sci 1991;32:3078-83.

17 Fleckenstein A. Prevention by verapamil of arterial calcium overload and concomitant lenticular calcification causing cataracts in alloxan-diabetic rats. In: Fleckenstein A, ed. Calcium antagonism in heart and smooth muscle. New York: John Wiley, 1984:280-5.

18 Pierce GN, Afzal N, Kroeger EA, et al. Cataract formation is prevented by administration of verapamil to diabetic rats. Endocrinology 1989;125:730-5.

19 Becher I. Untersuchungen über den Einfluß einer peroralen VerapamilApplikation auf die Entwicklung der Galaktosekatarakt bei Ratten [PhD Thesis]. Bonn: Friedrich-Wilhelms Universität, 1972.

20 Ett A, Hofmann U, Daxer A, et al. Ocular pharmacokinetics of verapamil in rabbits. Naunyn Schmiedebergs Arch Pharmacol 1998:357:331-5.

21 Clark JI, Mengel L, Bagg A, et al. Cortical opacity, calcium concentration and fiber membrane structure in the calf lens. Exp Eye Res 1980;31:399-410.

22 Rasband WS. NIH Image 1.61 Manual. Washington: Research Service Branch, National Institute of Health, (rsb.info.nih.gov/nih-image), 2002.
23 Rasband WS, Bright DS. NIH Image: a public domain image processing program for the Macintosh. Microbeam Analysis Society Journal 1995;4:137-49.

24 Jacob TJ. Three types of channel activity in frog lens epithelial cells [letter]. Exp Eye Res 1984;38:657-60.

25 Bhatnagar A, Ansari NH, Wang L, et al. Calcium-mediated disintegrative globulization of isolated ocular lens fibers mimics cataractogenesis. Exp Eye Res 1995:61:303-10.

26 Srivastava SK, Wang LF, Ansari NH, et al. Calcium homeostasis of isolated single cortical fibers of rat lens. Invest Ophthalmol Vis Sci 1997;38:2300-12.

27 Wang L, Bhatnagar A, Ansari NH, et al. Mechanism of calcium-induced disintegrative globulization of rat lens fiber cells. Invest Ophthalmol Vis Sci 1996:37:915-22.

28 Zernig G. Widening potential for $\mathrm{Ca}^{2+}$ antagonists: non-L-type $\mathrm{Ca}^{2+}$ channel interaction. Trends Pharmacol Sci 1990;11:38-44.

29 Borchman D, Delamere NA, Paterson CA. Ca-ATPase activity in the rabbit and bovine lens. Invest Ophthalmol Vis Sci 1988;29:982-7.

30 Duncan G, Webb SF, Dawson AP, et al. Calcium regulation in tissue-cultured human and bovine lens epithelial cells. Invest Ophthalmol Vis Sci 1993:34:2835-42.

31 Thomas GR, Sanderson J, Duncan G. Thapsigargin inhibits a potassium conductance and stimulates calcium influx in the intact rat lens. J Physiol (Lond) 1999;516:191-9

32 Ye JJ, Zadunaisky JA. $\mathrm{Ca}^{2+} / \mathrm{Na}^{+}$exchanger and $\mathrm{Na}^{+}, \mathrm{K}^{+} 2 \mathrm{Cl}^{-}$cotransporter in lens fiber plasma membrane vesicles. Exp Eye Res 1992:55:797-804.

33 Tomlinson J, Bannister SC, Croghan PC, et al. Analysis of rat lens $45 \mathrm{Ca}^{2+}$ fluxes: evidence for $\mathrm{Na}(+)-\mathrm{Ca}^{2+}$ exchange. Exp Eye Res 1991;52:619-27.

34 Williams MR, Duncan G, Riach RA, et al. Acetylcholine receptors are coupled to mobilization of intracellular calcium cultured human lens cells [letter]. Exp Eye Res 1993:57:381-4.

35 Thomas GR, Duncan G, Sanderson J. Acetylcholine-induced membrane potential oscillations in the intact lens. Invest Ophthalmol Vis Sci 1998:39:111-9.

36 Walsh SP, Patterson JW. Effects of hydrogen peroxide oxidation and calcium channel blockers on the equatorial potassium current of the frog lens. Exp Eye Res 1994; 58:257-65

37 Devamanoharan PS, Varma SD. Inhibition of polyol formation in rat lens by verapamil. J Ocul Pharmacol Ther 1995:11:527-31.

38 Muller P, Hockwin O, Ohrloff C. Comparison of aldose reductase inhibitors by determination of IC50 with bovine and rat lens extracts. Ophthalmic Res 1985;17:115-9.

39 Cammarata PR, Chen HQ, Yang J, et al. Modulation of myo-[3H]inositol uptake by glucose and sorbitol in cultured bovine lens epithelial cells. I. Restoration of myo-inositol uptake by aldose reductase inhibition. Invest Ophthalmol Vis Sci 1992;33:3561-71.

40 Lou MF, Dickerson JE Jr, Garadi R, et al. Glutathione depletion in the lens of galactosemic and diabetic rats. Exp Eye Res 1988;46:517-30.

41 Abelson MB, Gilbert CM, Smith LM. Sustained reduction of intraocular pressure in humans with the calcium channel blocker verapamil. Am J Ophthalmol 1988;105:155-9. 